\title{
Badania ultradźwiękowe powierzchni wewnętrznych otworów drążonych wałów turbin z wykorzystaniem fal powierzchniowych
}

\author{
Ultrasonic tests of the inner surface of hollow turbine shafts \\ with usage of surface waves
}

\section{Streszczenie}

W artykule przedstawiono automatyczną metodę ultradźwiękowego badania powierzchni wewnętrznych otworów drążonych wałów turbin o różnych średnicach na okoliczność wystąpienia pęknięć wzdłużnych i pęknięć poprzecznych. Na podstawie wykonanych głowic ultradźwiękowych porównano wyniki ze względu na różne sposoby wytwarzania fali powierzchniowej. W oparciu o wzorzec testowy opracowano wzorzec kalibracyjny układu. Przeprowadzono analizę możliwości wykrywania nieciągłości ze względu na ich głębokość. Opisano mechaniczną część układu opartą o śrubę pociągową i bezprzewodowy defektoskop CUD WiFI pozwalającą na pełną automatyzację badań.

Słowa kluczowe: osie drążone, wały turbin, fale powierzchniowe, badania ultradźwiękowe

\begin{abstract}
The paper presents automatic method of ultrasonic tests of hollow turbine shaft's inner surface. The goal of the test is to detect longitudinal and transverse flaws. On the basis of prepared ultrasonic probes results in view of different methods of forming surface waves was compared. Based on test pattern the calibration method for entire system was developed. Analysis of possibilities for detection of flaws due to their depth was made. Mechanical part of the system based on screw and wireless CUD WiFi flaw detector was described. That enables full automation of tests
\end{abstract}

Keywords: hollow axles, turbine shafts, surface waves, ultrasonic tests

\section{Wstęp}

Badania ultradźwiękowe wałów drążonych na okoliczność wystąpienia pęknięć poprzecznych wykonuje się od wielu lat, głównie w osiach kolejowych. Prosta geometria badania wymaga jedynie użycia systemu badań przeznaczonego do konkretnego rodzaju osi. Odpowiednia automatyzacja pozwala zaoszczędzić czas i pieniądze.

Geometria zewnętrzna wałów turbin jest bardzo skomplikowana, pełna kanalików i zmian średnic. Badana jest więc przy pomocy innych technik niż wspomniana, np. przy pomocy techniki PhasedArray. Ogromne obciążenia którym podlegają wały turbin w czasie pracy wymagają badań również powierzchni wewnętrznej otworu na okoliczność wystąpienia pęknięć. Ponadto odbiorcy takich badań żądają pełnego zapisu przebiegu badania. Z tego powodu oraz braku odpowiedniego dostępu wykonywanie tych badań przy pomocy metody penetracyjnej i magnetycznej nie jest możliwe. ZBM ULTRA Sp. z o.o. na zlecenie i we współpracy z Doosan Babcock Energy Sp. z o.o. opracowało więc system badań ultradźwiękowych z wykorzystaniem fal powierzchniowych.

Rzeczonych badań nie dotyczy żadna norma lub ogólnie stosowana procedura. Jej stworzenie jest więc jednym z elementów projektowanego systemu. Należy wyznaczyć wzorcowe nieciągłości sztuczne oraz poziomy akceptacji. Zarówno ZBM ULTRA jak i Doosan Babcock Energy nie mają informacji na temat awarii wirników turbin spowodowanych pęknięciami od strony powierzchni wewnętrznego otworu drążonego. Znane sa jednak przypadki wykrycia zapoczątkowania pęknięć, które wyeliminowano za pomocą butelkowania. Biorąc pod uwagę ogromne obciążenia w jakich pracują wirniki oraz ich cenę wykrywanie najmniejszych nawet nieciągłości jest bardzo istotne.

\section{Geometria badanych elementów i poszukiwane nieciągłości}

Badaniu podlega tylko powierzchnia wewnętrzna otworu drążonego. Z tego powodu geometria zewnętrzna wału jest dla nas nieistotna. Otwory drążone mają różną średnicę, w tym artykule analizowany jest wał z otworem drążonym

Mgr inż. Piotr Machała, mgr inż. Patryk Uchroński- ZBM ULTRA Sp. z o.o.

Autor korespondencyjny/Corresponding author. piotr.machala@ultra.wroclaw.pl 
o średnicy $\varnothing 90 \mathrm{~mm}$. Głowice są odpowiednio profilowane, więc badanie wału o innej średnicy wymagać będzie nowych głowic. Jednak podstawy fizyczne i opisane właściwości głowic będa takie same.

Przed projektowanym systemem badań postawiono zadanie wykrywania pęknięć poprzecznych i pęknięć wzdłużnych. Powierzchnia otworu wewnętrznego przed wykonaniem badań jest honowana, zapewniona jest więc odpowiednia gładkość powierzchni. Rozważanych badań nie obejmuje żadna norma. Jednym z zadań przy projektowaniu systemu było określenie minimalnej głębokości nacięć wzorcowych oraz dobranie poziomów akceptacji.

\section{Wzorce testowe i kalibracyjne}

Projektowanie systemu badania rozpoczęto od zaprojektowania i wykonania wzorca testowego. Jego schemat przedstawiono na rysunku 1.

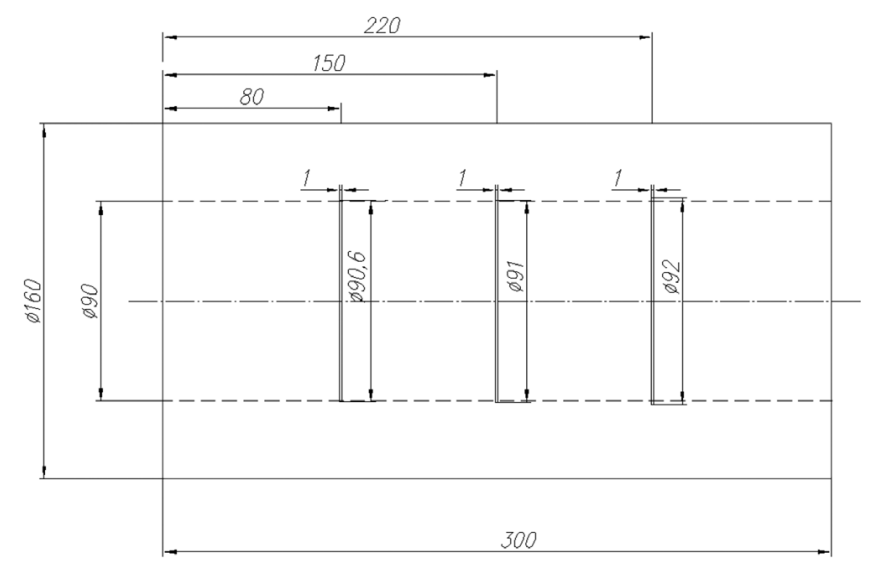

Rys. 1. Schemat wzorca testowego

Fig. 1. Scheme of test model

Na podstawie wykonanej analizy dobrano optymalne głębokości nacięć i wykonano wzorzec kalibracyjny, jego schemat przedstawiono na rysunku 2.

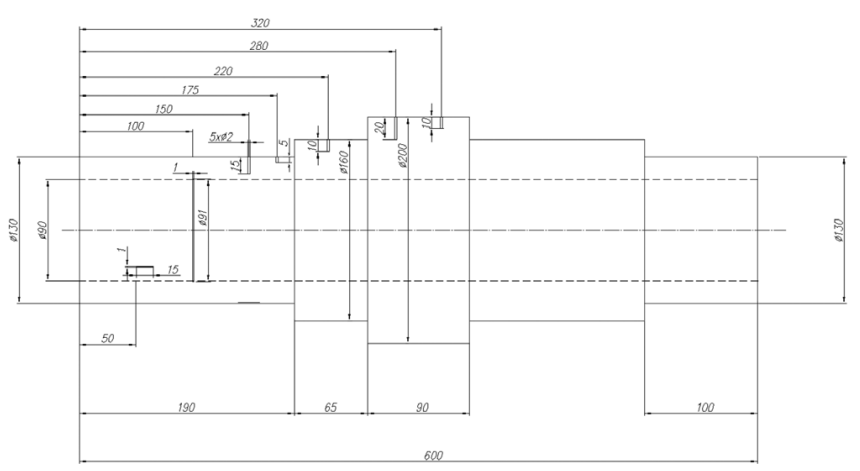

Rys. 2. Schemat wzorca kalibracyjnego

Fig. 2. Scheme of calibration model

\section{Zasady fizyczne wzbudzania fal powierzchniowych}

Rozważono i porównano dwie metody wzbudzania fal powierzchniowych:

- przy użyciu klina z plexi,

- przy użyciu przetwornika piezoelektrycznego w którego jeden wymiar jest mniejszy od długości fali.

Kąt a klinu z plexi jest tak dobrany, że kąt wprowadzania fali $\beta$ wynosi $90^{\circ}$. Dla stali wynosi on $64^{\circ}$, projektowanie głowic do badań materiałów płaskich (Rys. 3.) nie nastręcza większych problemów. W przypadku badań elementów drążonych na okoliczność wystąpienia pęknięć wzdłużnych należy pamiętać o odpowiednich długościach i profilowaniach klinu tak, aby środek ultradźwiękowy klinu pokrywał się z normalną badanej powierzchni (Rys. 4.).

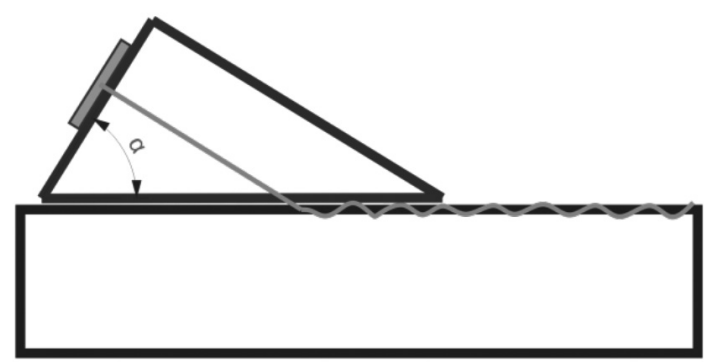

Rys. 3. Schemat klina podczas badań powierzchni płaskich Fig. 3. Scheme of wedge during tests of flat surfaces

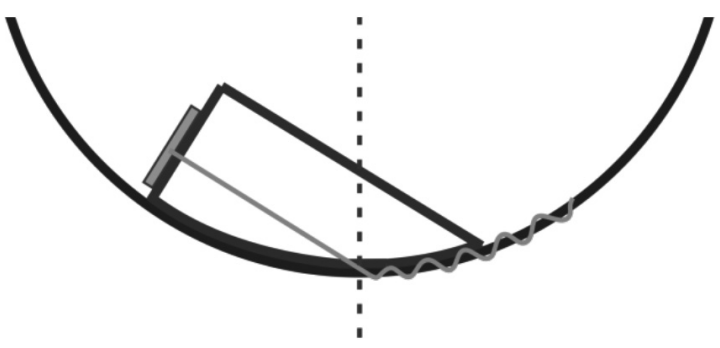

Rys. 4. Schemat klina podczas badań powierzchni profilowanych Fig. 4. Scheme of wedge during tests of profiled surfaces

Przetwornik posiadający jeden wymiar dużo mniejszy od dlugości fali wytwarza jednocześnie fale podłużne, poprzeczne i powierzchniowe. Dwa pierwsze rodzaje fal rozchodzą się przestrzennie, fale powierzchniowe natomiast wzdłuż powierzchni ośrodka. Natężenie tych ostatnich maleje z odległością wolniej niż natężenie fal podłużnych i poprzecznych. W większych odległościach od przetwornika możemy je zatem zaniedbać.

Metoda wytwarzania fal powierzchniowych za pomocą klina jest dużo częściej stosowana. Jednak ze względu na konieczność profilowania głowic do powierzchni badanej przeprowadzono analizę możliwości wykorzystania również drugiej metody.

\section{Analiza możliwości wykrywania nieciągłości}

Przeprowadzono analizę wykrywania nieciągłości sztucznych w postaci nacięć. Wszystkie użyte przetworniki i głowice miały częstotliwość $4 \mathrm{MHz}$.

W pierwszej kolejności na powierzchni płaskiej wykonano 3 nacięcia o głębokości 0,3; 0,5 i 1 mm. Dokonano pomiarów przy użyciu klina z przyklejonym przetwornikiem oraz samym przetowrnikiem nieobciążonym dla drugiej metody. Określono stosunek poziomu użytecznego do szumu, w tym celu echo od nacięcia ustawiono na $80 \%$ WE i dodawano wzmocnienie aż poziom szumów osiągnął $20 \%$ WE. Wyniki przedstawiono w tablicy I.

Wykonano analizę możliwości wykrywania nacięć wykonanych na powierzchni profilowanej z wykorzystaniem dwóch metod wytwarzania fali powierzchniowej.

Obie metody wytwarzania fali powierzchniowej dały obiecujące rezultaty, wykonano więc głowice w obudowach i osłonach przetwornika umożliwiające ich wykorzystanie w technice. Wykonano analogiczne próby jak te których efekty przedstawiono w tablicy I. 
Aby zapewnić ochronę małego przetwornika przed uszkodzeniami mechanicznymi w czasie pracy wykonano przylgę z kleju o grubości połowy długości fali. Obniżyła ona stosunek sygnału użytecznego do szumu do tego stopnia, że głowica wykonana z jej użyciem nie nadaje się do badań przemysłowych.

Zdecydowana się więc na wykonanie głowic profilowych z wykorzystaniem klina. Przed złożeniem układu mechanicznego wykonano analizę wykrywania nacięć na powierzchni profilowanej przy wykorzystaniu wzorca testowego. Okazało się, że geometria badania nie wpływa znacząco na otrzymywane rezultaty. Częściowe zalanie otworu olejem nie powoduje występowania ech pochodzących od granicy olej-powietrze.

Jako poziom akceptacji przyjęto echa od nacięć o głębokości 0,5 mm ustawione na 0,4 wysokości ekranu.

Tablica I. Określenie stosunku użytecznego to szumu przy użyciu różnych metod wytwarzania fal powierzchniowych i analizy ech od nacięć o różnej głębokości

Table I. Determination the ratio of useful signal to noise with usage of various methods for producing surface waves and analyzing the echoes from notches with different depth

\begin{tabular}{|c|c|c|c|c|}
\hline Lp. & $\begin{array}{c}\text { Metoda } \\
\text { wytwarzania fali }\end{array}$ & $\begin{array}{c}1 \text { nacięcie - } \\
\mathrm{h}=0,3 \mathrm{~mm}\end{array}$ & $\begin{array}{c}2 \text { nacięcie - } \\
\mathrm{h}=0,5 \mathrm{~mm}\end{array}$ & $\begin{array}{c}3 \text { nacięcie- } \\
\mathrm{h}=1 \mathrm{~mm}\end{array}$ \\
\hline 1 & $\begin{array}{c}\text { Z wykorzysta- } \\
\text { niem klina }\end{array}$ & $15 \mathrm{~dB}$ & $17 \mathrm{~dB}$ & $18 \mathrm{~dB}$ \\
\hline 2 & $\begin{array}{c}\text { Z wykorzysta- } \\
\text { niem małego } \\
\text { przetwornika }\end{array}$ & $16 \mathrm{~dB}$ & $18 \mathrm{~dB}$ & $21 \mathrm{~dB}$ \\
\hline
\end{tabular}

Tablica II. Określenie stosunku użytecznego to szumu przy użyciu gotowych głowic ultradźwiękowych

Table II. Determination the ratio of useful signal to noise with usage of finished probes

\begin{tabular}{|c|c|c|c|c|}
\hline Lp. & $\begin{array}{c}\text { Metoda } \\
\text { wytwarzania fali }\end{array}$ & $\begin{array}{c}1 \text { nacięcie - } \\
\mathrm{h}=0,3 \mathrm{~mm}\end{array}$ & $\begin{array}{c}2 \text { nacięcie - } \\
\mathrm{h}=0,5 \mathrm{~mm}\end{array}$ & $\begin{array}{c}3 \text { nacięcie - } \\
\mathrm{h}=1 \mathrm{~mm}\end{array}$ \\
\hline 1 & $\begin{array}{c}\text { Z wykorzysta- } \\
\text { niem klina }\end{array}$ & $15 \mathrm{~dB}$ & $17 \mathrm{~dB}$ & $18 \mathrm{~dB}$ \\
\hline 2 & $\begin{array}{c}\text { Z wykorzysta- } \\
\text { niem małego } \\
\text { przetwornika }\end{array}$ & $6 \mathrm{~dB}$ & $7 \mathrm{~dB}$ & $7 \mathrm{~dB}$ \\
\hline
\end{tabular}

\section{Mechaniczna część układu}

Zaprojektowany system został stworzony w oparciu o układ do badań kolejowych osi drążonych. Działa on z powodzeniem np. w zakładach Depas w Wilnie, Bombardier i Koleje Mazowieckie w Warszawie czy przy badaniu polskich składów typu Pendolino. System badań możemy podzielić na cztery części:

- bezprzewodowy defektoskop ultradźwiękowy CUD WiFi,

- głowice ultradźwiękowe,

- układ mechaniczny zapewniający obrót i przesuw,

- komputerowy program sterujący i archiwizujący.

Wielokanałowy bezprzewodowy defektoskop ultradźwiękowy CUD WiFi (Rys. 5.) został zaprojektowany jako podstawa automatycznych systemów badań. W standardzie może pracować na 10 kanałach równocześnie, lecz ta ilość może być praktycznie dowolnie powiększana. Bezprzewodowa łącznąść z komputerem, tabletem lub innym urządzeniem mobilnym posiadającym kartę WiFi umożliwia całkowitą rezygnacji z przewodów sygnałowych. Ma to szczególne znaczenie w analizowanym przypadku, ponieważ obracający układ powodowałby łamanie się przewodów sygnałowych.

Głowice ultradźwiękowe zostały doprofilowane do badanej powierzchni. W układzie zamontowano dwie głowice na fale powierzchniowe skierowane "w przód” i „w tył” do badań na okoliczność wystąpienia pęknięć poprzecznych, głowicę na fale powierzchniowe skierowaną zgodnie z kierunkiem obrotu układu do badań na okoliczność wystąpienia pęknięć wzdłużnych oraz dodatkowo głowicę podwójną normalną do wykrywania nieciągłości wewnątrz wału i głowicę na fale poprzeczne i kącie $45^{\circ}$ do przeszukiwania powierzchni zewnętrznej na okoliczność wystąpienia pęknięć poprzecznych. Główkę układu z głowicami ultradźwiękowymi przedstawiono na rysunku 6. Każda z głowic posiada niezależny układ dociskający ją do powierzchni badanej. Ma to ogromne znaczenie ponieważ w przypadku wystąpie-

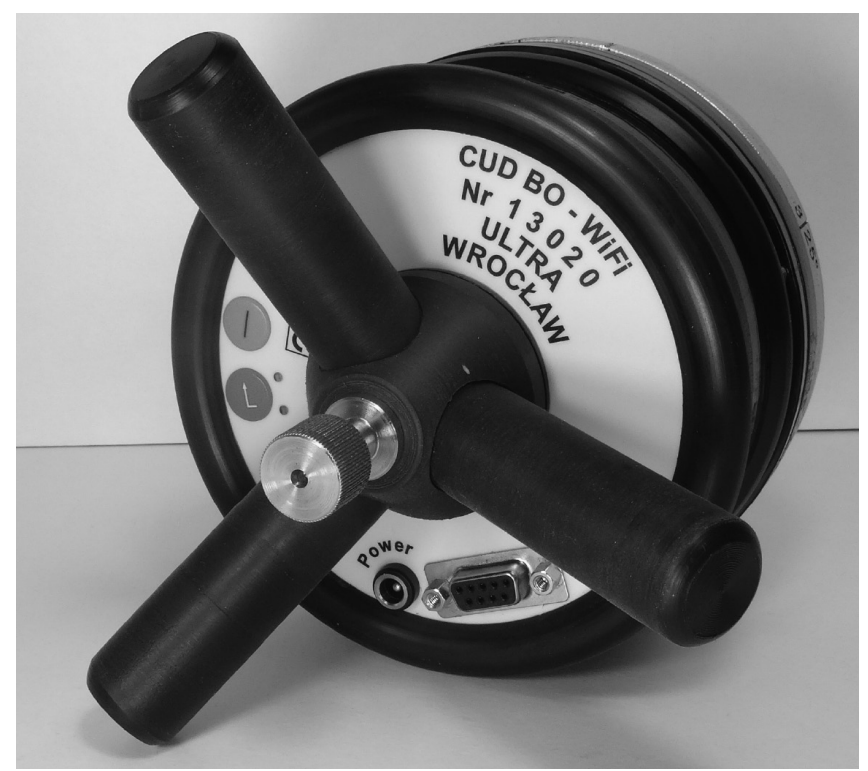

Rys. 5. Widok defektoskopu bezprzewodowego CUD WiFi Fig. 5. Wireless CUD WiFi flaw detector

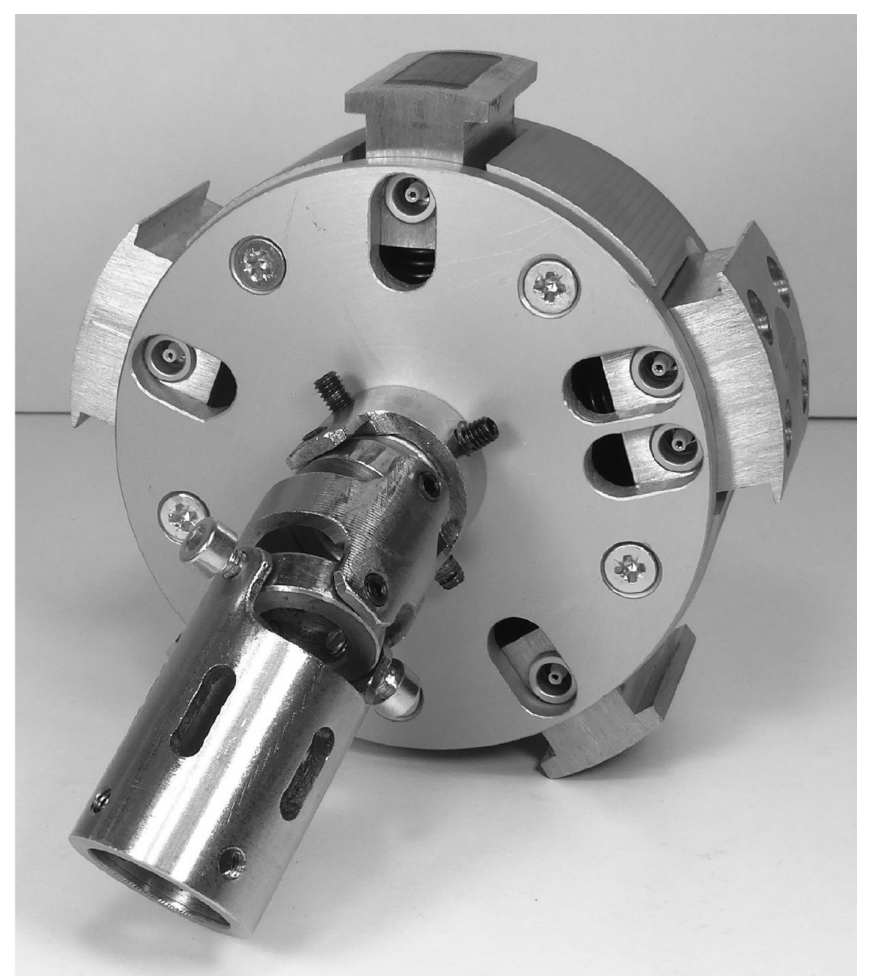

Rys. 6. Widok główki układu z głowicami ultradźwiękowymi Fig. 6. The head with ultrasonic probes 
nia nieciągłości wały turbin nie są wycofywane z eksploatacji tylko wykonuje się próby napraw nieakceptowalnego odcinka. W następstwie butelkowanie tworzy się fragmentaryczne powiększenie średnicy otworu wewnętrznego. Głowice muszą więc same dociskać się do badanej powierzchni.

Układ mechaniczny został oparty o śrubę pociągową i zapewnia automatyczny przesuw i obrót głowic. Dzięki temu zbadana zostaje cała powierzchnia otworu wewnętrznego. Układ mechaniczny przedstawiono na rysunku 7.

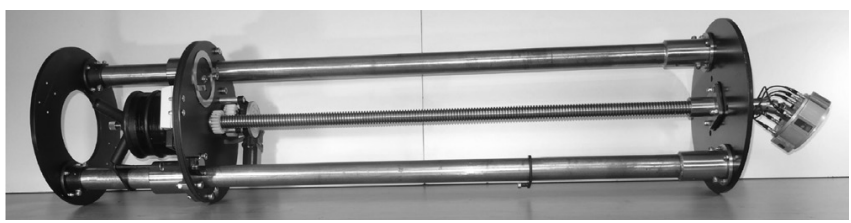

Rys. 7. Układ mechaniczny systemu

Fig. 7. Mechanical part of the system

Komputerowy programu sterujący pozwala na obserwację zobrazowania A-scan każdej głowicy osobno i wszystkich równocześnie. Dzięki pomiarowi kątów i zliczania obrotów układu możliwa jest dokładna identyfikacja położenia głowic, a więc i położenia wykrytych nieciągłości. Zrzut ekranu komputerowego programu sterującego przedstawiono na rysunku 8. Program dokonuje zapisu całego przebiegu badania, a nie tylko ewentualnych wskazań powyżej progu akceptacji. Na rysunku 9 przedstawiono przykładowy wynik zbiorczy badania.

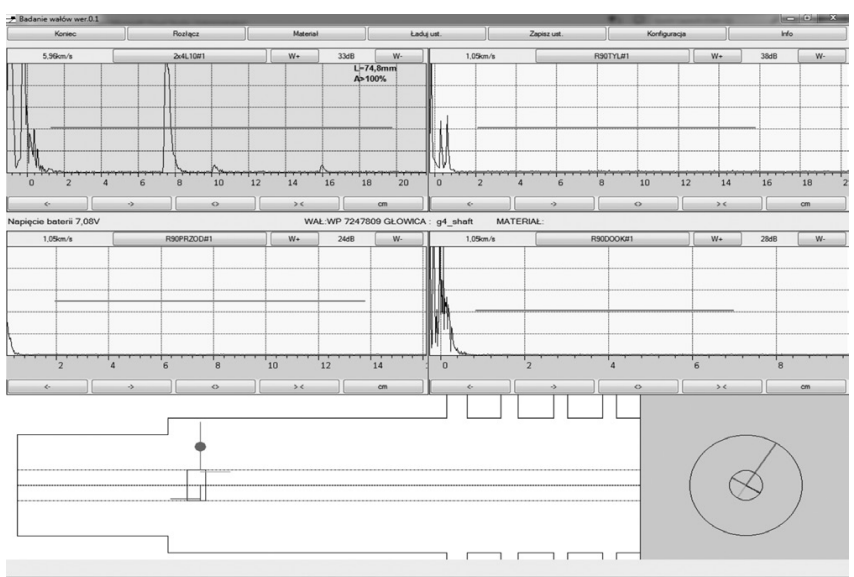

Rys. 8. Zrzut ekranu komputerowego programu sterującego Fig. 8. Print screen of computer control program

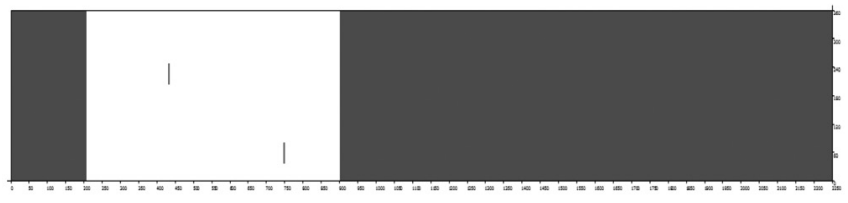

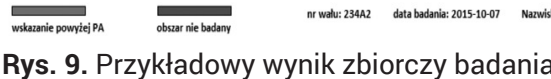

Fig. 9. Exemplary comultative test result

\section{Podsumowanie}

Przedstawiony system jest obecnie testowany przez Doosan Babcock Energy w Rybniku. Spełnia on wszystkie wymagania zamawiającego, tj. wykrywanie pęknięć poprzecznych i pęknięć wzdłużnych otworu drążonego oraz rejestracja całego przebiegu badania. Rozwinięciem systemu może być dodanie modułu prądów wirowych. Wówczas powierzchnia wewnętrzna otworu drążonego będzie badana za pomocą dwóch różnych metod, co podniesie wiarygodność badań.

\section{Literatura}

[1] Filipczyński L., Pawłowski Z., Wehr J., Ultradźwiękowe metody badań materiałów, Warszawa, Państwowe Wydawnictwa Techniczne, 1959.

[2] Michnowski W., Machała P., Mierzwa J., Uchroński P., Bezpieczeństwo eksploatacji osi kolejowych i badania ultradźwiękowe, 43 Krajowa Konferencja Badań Nieniszczących, 2014.

\section{ZAMÓW NEWSLETTER}

\section{Zapraszamy Państwa do zapisania się na bezpłatny}

NEWSLETTER Przeglądu Spawalnictwa, w tym celu należy wysłać e-mail z tematem “NEWSLETTER” na adres: redakcja@pspaw.pl

\section{SPAWR przeglad}

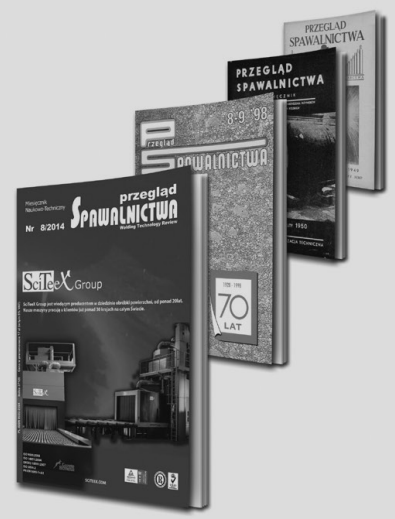

